\title{
Stimulating Effect of Red Beetroot (Beta vulgaris) Juice, Fractioned by Membrane Ultrafiltration, on Iron Absorption in Chicken Intestines
}

\author{
D. Babarykin 1 , G. Smirnova ${ }^{1,2}$, G. Krumina ${ }^{1}$, S. Vasiljeva ${ }^{2}$, Z. Krumina ${ }^{1}$, N. Basova ${ }^{2}$, A. Fedotova ${ }^{1}$ \\ ${ }^{1}$ Institute of Innovative Biomedical Technology Ltd., Riga, Latvia \\ ${ }^{2}$ Institute of Biology of the University of Latvia, Riga, Latvia \\ Email: dmitry.b@parks.lv
}

How to cite this paper: Babarykin, D., Smirnova, G., Krumina, G., Vasiljeva, S., Krumina, Z., Basova, N. and Fedotova, A. (2018) Stimulating Effect of Red Beetroot (Beta vulgaris) Juice, Fractioned by Membrane Ultrafiltration, on Iron Absorption in Chicken Intestines. Journal of Biosciences and Medicines, 6, 37-49.

https://doi.org/10.4236/jbm.2018.611005

Received: August 16, 2018

Accepted: November 13, 2018

Published: November 16, 2018

Copyright $(9) 2018$ by authors and Scientific Research Publishing Inc. This work is licensed under the Creative Commons Attribution International License (CC BY 4.0).

http://creativecommons.org/licenses/by/4.0/

\begin{abstract}
Iron deficiency is one of the leading risk factors for disability and death worldwide. Targeted iron supplementation with pharmaceuticals is widely used, but oral iron salt ingestion often causes side effects-nausea, vomiting, abdominal pain. The present study demonstrated that red beetroot juice (RBRJ) contains a compound or compound complex with the ability to specifically stimulate duodenal iron absorption, shown in experiments in vitro, in situ and in vivo. The effect does not depend on juice sugar and ascorbic acid concentration. Fractionated RBRJ impact on iron absorption is dose dependent. This phenomenon is described for the first time.
\end{abstract}

\section{Keywords}

Iron Intestinal Absorption, Red Beetroot Juice, Ultrafiltration, Chickens

\section{Introduction}

Iron is found in almost all foods, so dietary iron intake is related to energy intake. However, its availability for absorption is quite variable, and poor bioavailability is a major reason for the high prevalence of nutritional iron deficiency anemia [1]. The body's need for iron depends on organism physiological status (pregnancy, old age, regular exercise, stress). Nutritional iron deficiency arises when physiological requirements cannot be met by iron absorption from the diet. Some pathological conditions cause secondary iron deficiency. There are also a lot of genetic forms of iron-related anemia [2]. 
Iron deficiency is one of the leading risk factors for disability and death worldwide, affecting an estimated 2 billion people [3]. Iron deficiency anaemia (IDA) prevalence varies widely: $7.2 \%$ - $14 \%$ in Italy, Belgium, Germany, Spain [4], 32.8\% in Croatia [5] and 60\% in Asian countries, females of reproductive age [6].

Targeted iron supplementation with pharmaceuticals is widely used, but oral iron salt ingestion often causes side effects-nausea, vomiting, abdominal pain [7]. Oral iron supplementation leads to an improved blood hemoglobin level, but at the cost of increased oxidative stress [8].

Many attempts have been made to improve food iron bioavailability by diet enrichment with fruits and vegetables. One of the most important plant compounds which enhance iron absorption is ascorbic as well as other organic acids [9]. In the experiment in vitro and in situ we previously showed a positive correlation between the ascorbic acid level in mucosal buffer solutions and iron duodenal absorption in chickens [10].

Nevertheless, increased fruit and vegetable consumption is not a panacea. Plants specific effects are not always targeted on iron bioavailability increase. For example, red grape juice diminishes iron availability [11]. Orange and apple juices stimulate iron absorption from the meal in children [12]. Common beans (Phaseolus vulgaris) are a staple food and the major source of iron for populations in Eastern Africa and Latin America. Bean iron concentration is high but with low bioavailability due to inhibitory compounds such as phytic acid [13] and polyphenols [14].

Attention is drawn by the fact that practically all attempts to stimulate iron assimilation in humans are targeted on food fortification with iron-containing substances or on iron bioavailability increase. Legume seeds are a traditional source of iron and ferritin, which increases iron bioavailability. However, even if the percentage of ferritin iron in these seeds is high, its concentration is not sufficient for food fortification. Thus, legume seeds, as well as other plant seeds, need to be fortified with iron [15]. We did not find any publication regarding the ability of plants to directly stimulate active iron ion transport via the intestinal wall. In this regard, some interesting facts may be found in the arsenal of traditional medicine.

In this regard, red beetroot (Beta vulgaris) should be mentioned in the first place. Cultivated forms of red beet have been used for their medicinal properties since ancient times. Beetroot has long been considered beneficial to the blood, the heart and the digestive system [16]. Usually red beetroot anti-anemic effects are associated with high iron concentration in the juice. Published scientific data regarding red beetroot impact on iron metabolism were not found.

The aim of the study was to evaluate the influence of red beetroot juice as well as other vegetable juices on iron intestinal absorption in the cockerels. The interface between cellular and systemic iron homeostasis is readily observed in the highly dynamic iron handling of four main cell types: duodenal enterocytes, en- 
terocytes precursors, macrophages and hepatocytes [17]. Consequently, manipulations with duodenum, predominantly, in vitro and in situ were used to reach the objective of the study.

\section{Materials and Methods}

\subsection{Vegetable Juices}

\subsubsection{Native Juices}

Zucchini, carrot, cucumber, pumpkin, red beetroot, sugar beetroot and fodder beetroot were delivered by a local farmer in September 2016. Using a household juicer, the vegetable juice was squeezed, processed by centrifuge for $15 \mathrm{~min}$ at $5000 \mathrm{~g}$. The obtained juices were tested for iron, ascorbic acid, glucose, fructose, sucrose level as well as pigments (betanin which belongs to the red pigment group; vulgaxantin-I as a yellow pigment component).

\subsubsection{Fermentative Red Beetroot Juice (RBRJ)}

An additional experiment was conducted using sugar-free red beetroot juice (RBRJ). Fresh RBRJ was diluted with distilled water (10\% added), fermented for $48 \mathrm{~h}\left(\right.$ at $\left.25^{\circ} \mathrm{C}\right)$ using a dried and previously activated culture of Saccharomyces cereviseae $(2 \mathrm{~g} / \mathrm{L})$, filtrated via paper and processed by centrifuge for $20 \mathrm{~min}$ at $5000 \mathrm{~g}$. The centrifugate was evaporated to the initial juice volume in vacuum at $40^{\circ} \mathrm{C}$ to remove the ethanol. Sucrose concentration dynamics was checked.

\subsubsection{Fractionated RBRJ. Red Beetroot Juice Fractionation Method Development}

To increase RBRJ specific activity, the ultrafiltration method was used. Ultrafiltration is usable to fractionate juices or plant extracts through separation by molecular mass. Fresh RBRJ was processed by centrifuge for $20 \mathrm{~min}$ at $5000 \mathrm{~g}$ followed by ultrafiltration using "Ultracel" membranes with cut-off-point 250 - 200 - 150 - 50 - 20 - or $1 \mathrm{kDa}$. Juice permeate was collected for chemical and functional testing.

\subsection{Animals}

30-day-old Lohmann Brown cockerels were used in the study. The chickens were housed in cage units with free access to food and water. The animals were fed a wheat-barley full-feed diet containing all necessary nutrients. The iron concentration in the diet was $329 \pm 7 \mu \mathrm{g} / \mathrm{kg}$, the ascorbic acid content was $35.5 \pm$ $1.2 \mu \mathrm{g} / \mathrm{kg}$.

At the end of the experiment, the cockerels were decapitated in accordance with the recommendations for the euthanasia of experimental animals of the European Convention [18]. The experiment was approved by the local Animal Ethics Committee.

\subsection{Study Design}

The obtained vegetable juices were used in vitro, in situ and in vivo experiments 
in chickens. To identify vegetable ability to stimulate iron intestinal absorption, the screening of plant juices was performed. The RBRJ effect was analyzed in detail. The study included the following experiments:

- Vegetable juice impact on iron intestinal absorption in vitro;

- RBRJ fractionation method development;

- Fractionated RBRJ effects on iron absorption evaluation.

\subsubsection{In Vitro Study}

Juice samples were evaluated for their ability to stimulate iron absorption of the chicken's intestinal mucosa in vitro. Fe binding by the intestinal wall was studied by means of accumulating mucosal preparation (AMP) as developed by Ugolev et al. [19] for investigation of the initial absorption process. After the birds were decapitated, four AMP (each $4.5 \mathrm{~cm}$ long) were prepared from the duodenum, but from the jejunum-two. AMP everted the gut mucosa outside. An everted intestinal segment, mounted on a glass rod, was submerged in $7 \mathrm{~mL}$ Tris-buffer containing $0.512 \mathrm{mM} \mathrm{Fe}^{2+}$ or buffered tested vegetablejuice, and incubated for 30 min at $40^{\circ}$. The amount of accumulated iron was calculated as the difference between the iron contents of the mucosa before and after incubation. Buffer composition (mM) was: 4 Trishydrochloride, $145 \mathrm{NaCl}, 4 \mathrm{KCl}, 20$ fructose, $\mathrm{pH}$ 7.4. With the aim of evaluating the potential impact of iron absorption stimulating substances (ascorbic acid and sucrose) on iron absorption, in an in vitro experiment AMP were incubated in the buffer, containing the mentioned substances.

\subsubsection{In Situ Study}

Fe absorption was studied in duodenum. Before the absorption studies, cockerels were fasted for 16 - $18 \mathrm{~h}$. During the experiment, chickens were kept under diethyl ether anesthesia. An isolated duodenal loop was filled with $0.5 \mathrm{~mL}$ buffer solution. Buffer composition (mM) was as follows: 13.7 Tris hydrochloride, 119 sodium chloride, 4.74 potassium chloride, 20 fructose, $\mathrm{pH} 7.4$; in the buffer solution infused into duodenal sacs, $\mathrm{Fe}^{2+}$ concentration was $400 \mu \mathrm{g} / \mathrm{mL}(7.16 \mathrm{mM})$. After 30 minutes, vein ( $V$. jugularis) blood sampling was done. The chickens were decapitated, the liver and an isolated intestine segment removed. The contents were drained into a test-tube; segments were rinsed with $1 \mathrm{~mL} 154 \mathrm{mM}$ $\mathrm{NaCl}$ and put into a separate test-tube. The amount of Fe absorbed was calculated as the difference between Fe content just after the infusion and 30 minutes later and expressed as $\mathrm{nmol} / \mathrm{g}$ tissue. In this experiment iron absorption in duodenum, as well as accumulation in the liver, were compared for ingested buffer solution enriched with $\mathrm{FeSO}_{4}$ buffer plus native or fractionated RBRJ.

\subsubsection{In Vivo Study}

In vivo dose-dependence of RBRJ and its fractional impact on iron accumulation in duodenal mucosa was also studied. Five different concentrations of juice or its fraction were used. 30-day-old chicks were orally given $1 \mathrm{~mL}$ of 5 -fold concentrated by lyophilization, 2 -fold concentrated, native, 2 diluted, 5 diluted juices or 
fraction in distilled water together with $1 \mathrm{~mL}$ ferrous II sulfate solution $\left(\mathrm{Fe}^{2+} 0.4\right.$ $\mathrm{mg} / \mathrm{mL}$ ) $90 \mathrm{~min}$ before decapitation. The duodenum (intestinal content and mucosa) was then analyzed for iron content.

\subsection{Laboratory Determinations}

Fe concentrations in organs and tissues were estimated after dry aching in atomic absorption spectrophotometer (Perkin-Elmer, Analyst 700) [20]. Ascorbic acid concentration in beet juice and fractions was determined by 2,6-dichlorindophenol titrimetric method [21].

Total sugar and reducing sugar were determined according to the AOAC Official Method 974.06 [22] and the Nelson-Somogyi assay with copper and arsenomolybdate reagents [23], respectively, ethanol by AOAC Official Method 942.06 [24]. The content of pigments in vegetable juices and RBRJ fractions was determined by spectrophotometric method [25].

\subsection{Statistics}

All statistics were performed using the program SPSS. Means and Standard deviations and significance values were calculated. Results are presented as mean \pm S.E.M. Statistical comparisons were performed using Student's t-test. Statistical significance was set at $\mathrm{P}<0.05$.

\section{Results}

Chemical composition of tested vegetable juices is shown in Table 1. The highest iron and ascorbic acid concentration were found in zucchini and red beetroot juice.

In the in vitro experiment, the effect of vegetable juice on iron absorption in chicken intestines was tested. The most intensive iron accumulation occurred in duodenum and the maximal stimulating effect was caused by RBRJ (Table 2).

The impact of Beta vulgaris colored andpigment-free juice strains on iron absorption was studied in vitro (Table 3). RBRJ, in comparison with sugar beet and fodder beetroot, stimulates iron absorption $17.5 \%$ and $29.0 \%$ more, respectively.

Table 1. Vegetable juice chemical composition.

\begin{tabular}{cccccccc}
\hline Vegetable & $\mathrm{Fe}$ & Reducing & Sucrose & Betanin & Vulgaxantin-I & Ascorbic & $\mathrm{pH}$ \\
\hline Juice & $\mu \mathrm{g} / \mathrm{mL}$ & sugars, $\mathrm{g} / \mathrm{L}$ & $\mathrm{g} / \mathrm{L}$ & $\mathrm{mg} / \mathrm{L}$ & $\mathrm{mg} / \mathrm{L}$ & Acid, $\mathrm{mM}$ & \\
\hline Cucumber & 1.25 & 1.5 & 11 & 0 & 0 & 0.57 & 6.2 \\
Pumpkin & 1.13 & 5.1 & 12 & 0 & 0 & 0.56 & 6.6 \\
Zucchini & 2.13 & 3.0 & 20 & 0 & 0 & 0.81 & 7.0 \\
Carrot & 1.75 & 25.0 & 35 & 0 & 0 & 0.52 & 7.1 \\
Red beetroot & 3.08 & 4.0 & 60 & 770.0 & 581.0 & 0.84 & 6.6 \\
Sugar beetroot & 1.18 & 19.0 & 158 & 2.5 & 55.0 & 0.74 & 6.2 \\
Fodder beetroot & 1.01 & 21.0 & 74 & 0 & 96.0 & 0.77 & 6.5 \\
\hline
\end{tabular}


Table 2. Vegetable juice impact on Fe absorption by intestinal mucosa in vitro studies ${ }^{\mathrm{a}}$.

\begin{tabular}{|c|c|c|}
\hline \multirow[t]{3}{*}{ Incubation medium composition ${ }^{a}$} & \multicolumn{2}{|c|}{ Iron content in intestinal mucosa $(\mu \mathrm{g} / \mathrm{g})$} \\
\hline & \multicolumn{2}{|c|}{ In $30 \mathrm{~min}$ of incubation at $40^{\circ} \mathrm{C}(\mathrm{n}=20)$} \\
\hline & Duodenum & Jejunum \\
\hline Buffered zucchini juice & $9.80 \pm 0.58^{\star * *}$ & $3.84 \pm 0.22^{*}$ \\
\hline Buffered carrot juice & $9.15 \pm 0.69^{* * *}$ & $5.14 \pm 0.72^{* *}$ \\
\hline Buffered cucumber juice & $8.15 \pm 0.38^{*}$ & $6.89 \pm 0.42^{* * * *}$ \\
\hline Buffered pumpkin juice & $8.12 \pm 0.38^{*}$ & $5.12 \pm 0.37^{\star}$ \\
\hline Buffered red beetroot juice & $14.31 \pm 0.55$ & $10.38 \pm 1.46$ \\
\hline Buffered sugar beetroot juice & $11.80 \pm 0.37$ & $8.14 \pm 0.45$ \\
\hline Buffered fodder beetroot juice & $10.14 \pm 0.78$ & $7.12 \pm 0.52$ \\
\hline Tris-buffer & $8.91 \pm 0.19$ & $3.36 \pm 0.49$ \\
\hline
\end{tabular}

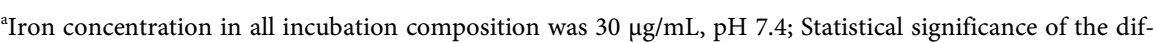
ferences between juices was calculated in comparison with red beetroot: ${ }^{*} \mathrm{p}<0.001$; ${ }^{* *} \mathrm{p}<0.002$; ${ }^{* * *} \mathrm{p}<$ $0.003 ;{ }^{* * * *} \mathrm{p}<0.02$

Table 3. Native and fractionated (cut-off-point $150 \mathrm{kDa}$ ) red beetroot juice chemical composition.

\begin{tabular}{ccc}
\hline Compounds & Native red beetroot juice & Fractionated red beetroot juice \\
\hline Iron, $\mu \mathrm{g} / \mathrm{L}$ & 3.13 & 2.0 \\
Ascorbic acid mM & 0.9 & 0.8 \\
Glucose, g/L & 1.13 & 1.2 \\
Sucrose, g/L & 52.0 & 54.0 \\
Fructose, g/L & 0.5 & 0.45 \\
Betanin, mg/L & 743.0 & 642.0 \\
Vulgaxantin-I, mg/L & 424.0 & 324.0 \\
Total phenols $(\mathrm{GAE}, \mathrm{mg} / \mathrm{L})$ & 22.4 & 20.1 \\
\hline
\end{tabular}

Ascorbic acid concentration in RBRJ was a little higher than in sugar beet and fodder beetroot. However, sugar content in colored beet strains was less than in uncolored ones. Red pigment betanin is a component of red beetroot only, while yellow vulgaxantin-I is found in all tested Beta vulgaris varieties. The effect of some red beetroot components was tested in a special experiment (Figure 1(a), (Figure 1(b)). To compare the potential role of red beetroot sugar in iron intestinal transport stimulation, it was compared for native and fermented juice effects (Figure 1(a)). Due to fermentation, the total sugar content in red beetroot juice decreased from $5.20 \%$ (including reducing sugars $0.19 \%$ ) to $0.57 \%$ (reducing sugars $0.06 \%$ ), but this fact did not diminish the iron content in duodenal mucosa after daily oral ingestion for one week of $2 \mathrm{~mL}$ of tested juice: $18.7 \pm 1.3$ $\mu \mathrm{g} / \mathrm{g}$ for native juice and $19.4 \pm 1.1 \mu \mathrm{g} / \mathrm{g}(\mathrm{p}>0.05)$ for fermented juice.

In vitro experiments showed $55 \%$ less active iron absorption by the duodenal 


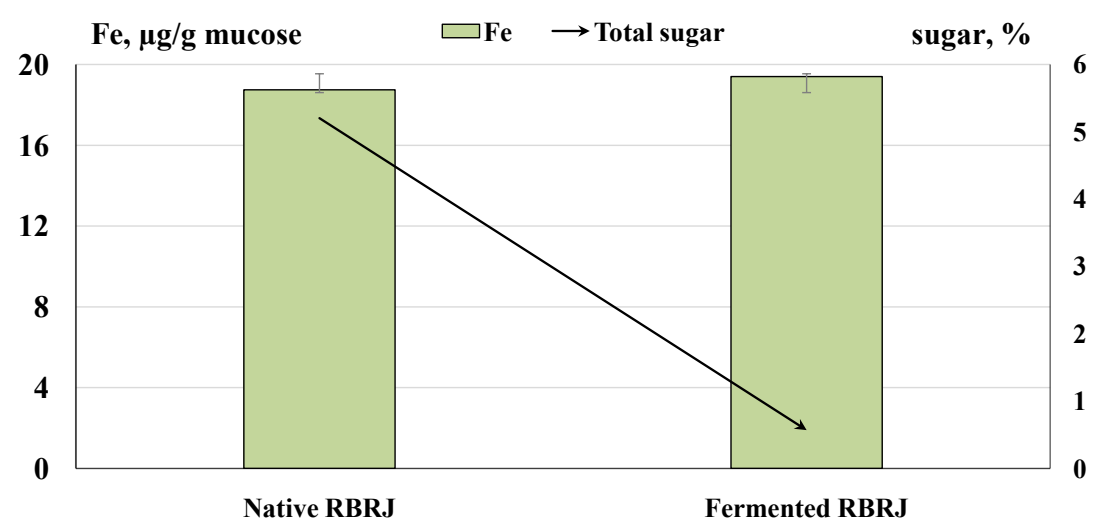

(a)

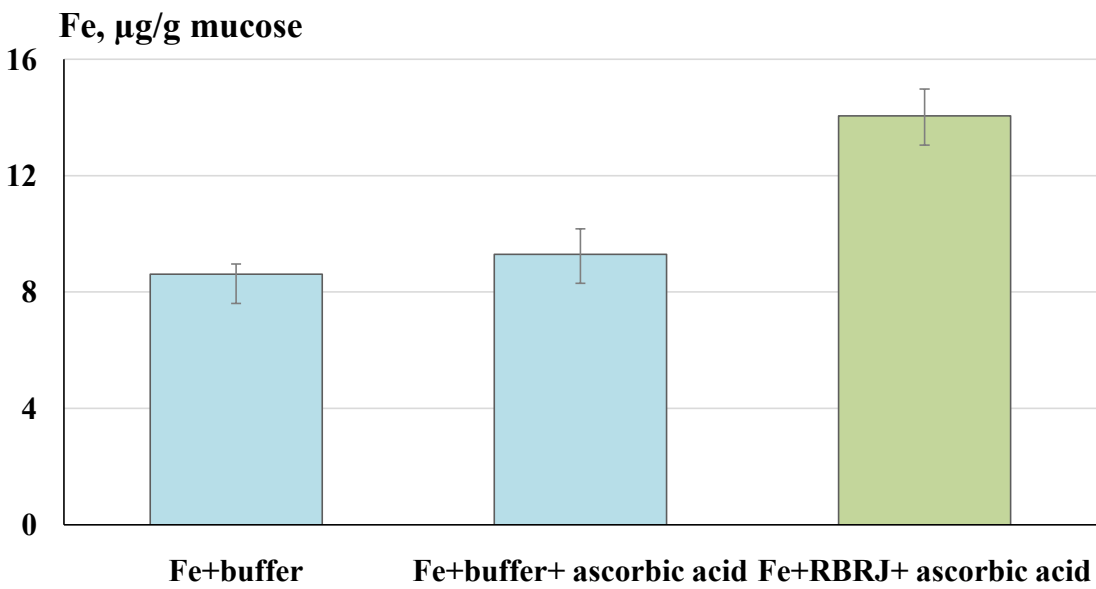

(b)

Figure 1. Influence of red beetroot juice (RBRJ) sucrose in vivo (a) and ascorbic acid in vitro (b) on Fe absorption in duodenum of chickens.

mucosa stimulator in comparison with RBRJ with equimolar ascorbic acid level Figure 1(b).

With the goal of increasing red beetroot juice specific functionality, native red beetroot juice was subjected to fractionation using an ultrafiltration method. Prepared red beetroot permeates (i.e. six fractions) were tested for iron content and its ability to stimulate iron intestinal absorption in vitro.

As seen in Figure 2, fraction III (it corresponds to cut-off-point $150 \mathrm{kDa}$ ) showed maximal ability to stimulate iron accumulation in duodenal mucosa.

Chemical composition of RBRJ and its fraction is shown in the Table 3.

Iron liver accumulation is an integral indicator characterizing intestinal ion absorption. Table 4 demonstrates the effect of fractionated RBRJ on iron absorption and liver accumulation in chickens. Fractionated as well as native red beetroot juice was tested in situ. During 30 minutes, $14 \%$ of ingested iron was absorbed, but in the case of fractionated RBRJ-34.5\%, from the chicken's duodenum in the presence of native RBRJ. In comparison with native juice, the fractionated one also increased iron accumulation in the liver.

In a separate experiment the dose dependence of iron intestinal absorption 


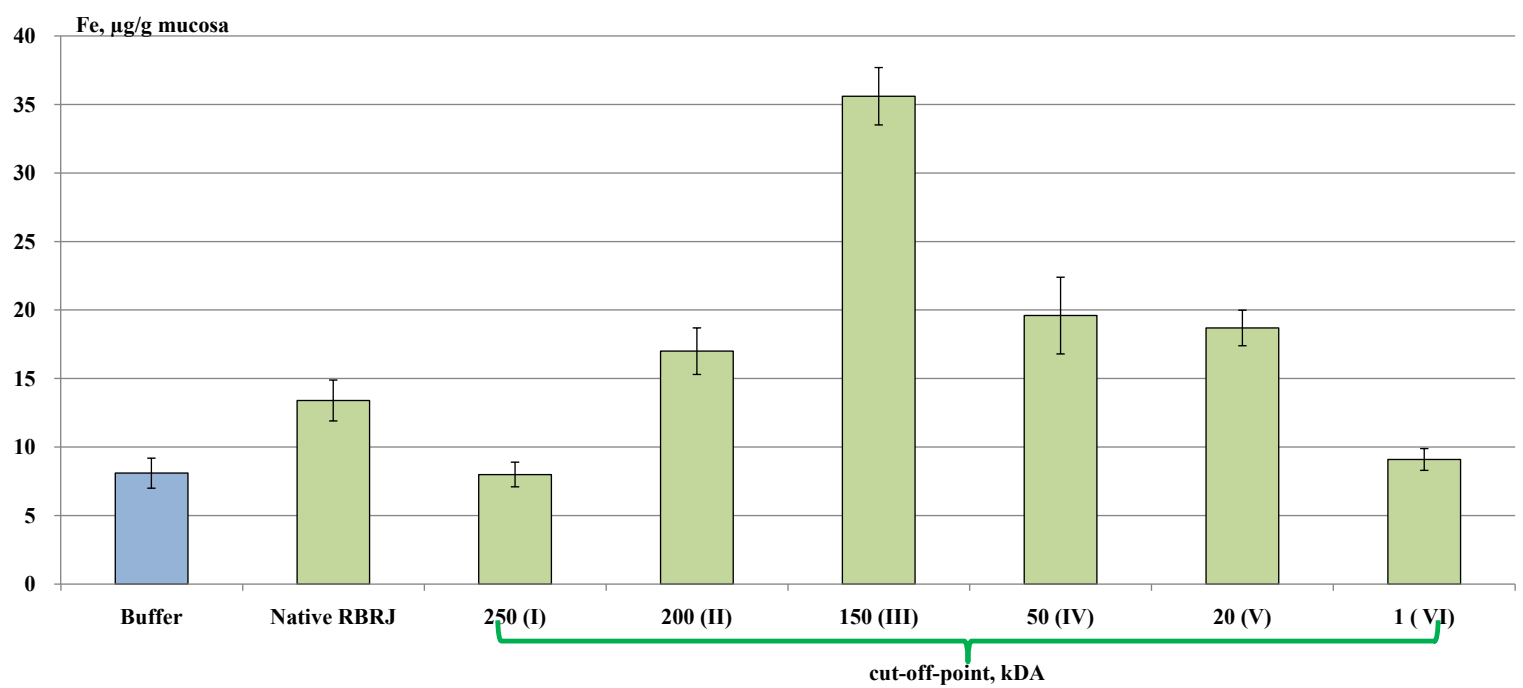

Figure 2. Red beetroot juice (RBRJ) fractions obtained by ultrafiltration impact on iron accumulation in chicken duodenal mucosa in vitro. All fractions were normalized on $\mathrm{Fe}^{2+}$ concentration $(28.6 \mu \mathrm{g} / \mathrm{mL})$ by adding iron II sulfate.

Table 4. Impact of native and fractionated red beetroot juice (RBRJ) on iron duodenal absorption and accumulation in the liver in situ.

\begin{tabular}{cccc}
\hline Group $\mathrm{Nr}$ & Tested solution & Duodenum & Liver \\
\hline & Composition & Fe, \% of absorption & $\mathrm{Fe}, \mu \mathrm{g} / \mathrm{g}$ \\
\hline 1. & $\begin{array}{c}\text { Buffer solution } \\
\mathrm{Fe}^{2+}(400 \mu \mathrm{g} / \mathrm{mL})^{* *}\end{array}$ & 8.2 & $144.25 \pm 9.11$ \\
2. & Native RBRJ & 14.0 & $148.00 \pm 3.90$ \\
& $\mathrm{Fe}^{2+}(400 \mu \mathrm{g} / \mathrm{mL})^{* *}$ & & \\
3. & $\mathrm{Fractionated} \mathrm{RBRJ}$ & 34.5 & $176.90 \pm 4.03^{* * *}$ \\
\hline
\end{tabular}

${ }^{*}$ Buffer's composition: $13.7 \mathrm{mM}$ Tris; $119 \mathrm{mM} \mathrm{NaCl} ; 4.74 \mathrm{mM} \mathrm{KCl} ; 20 \mathrm{mM}$ fructose, $\mathrm{pH} 7.4$; ${ }^{* *} \mathrm{Fe}^{2+}$ as Fe$\mathrm{SO}_{4} 7 \mathrm{H}_{2} \mathrm{O} ;{ }^{* *}$ Compared differences between native and fractionated RBRJ: $\mathrm{p}<0.001$.

and liver accumulation from per os ingested RBRJ were evaluated in vivo (Figure 3 and Figure 4).

It is interesting to note that, unlike native juice, the effect of fractionated RBRJ on both iron intestinal absorption and liver accumulation was dose dependent.

\section{Discussion}

The objective of the research was to find a plant (vegetable) with a high ability to stimulate intestinal active transport of iron. Studying the impact of a vegetable's native juice on the iron absorption in chicken intestines using modeling system in vitro (AMP), it was shown that RBRJ causes a most marked effect and it does not depend on juice ascorbic acid concentration, which is one of the most important natural iron assimilation promoters (Table 1 and Table 2). Probably, it is about stimulating iron active transport in enterocytes, because in vitro experiments ions flow increased against concentration gradient. 


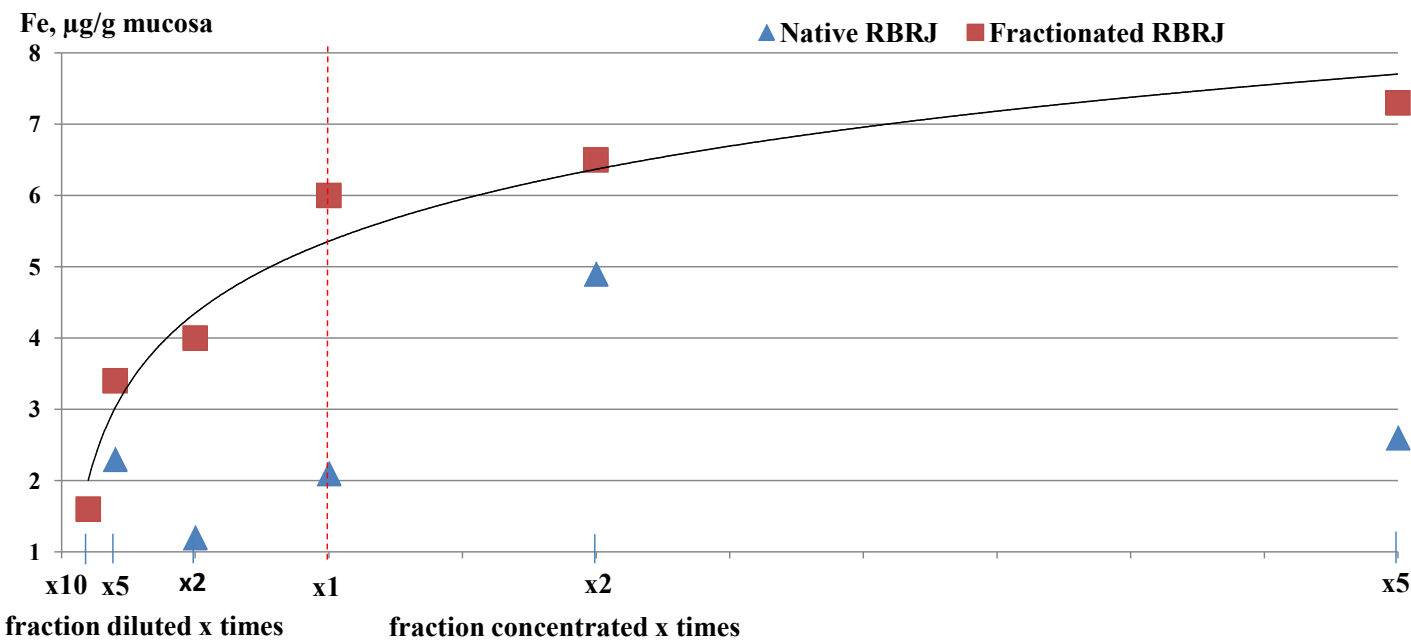

fraction diluted $x$ times fraction concentrated $x$ times

Figure 3. The effect of a single per os ingestion of native or fractionated red beetroot juice (RBRJ) on the content of iron in chicken duodenum in vivo.

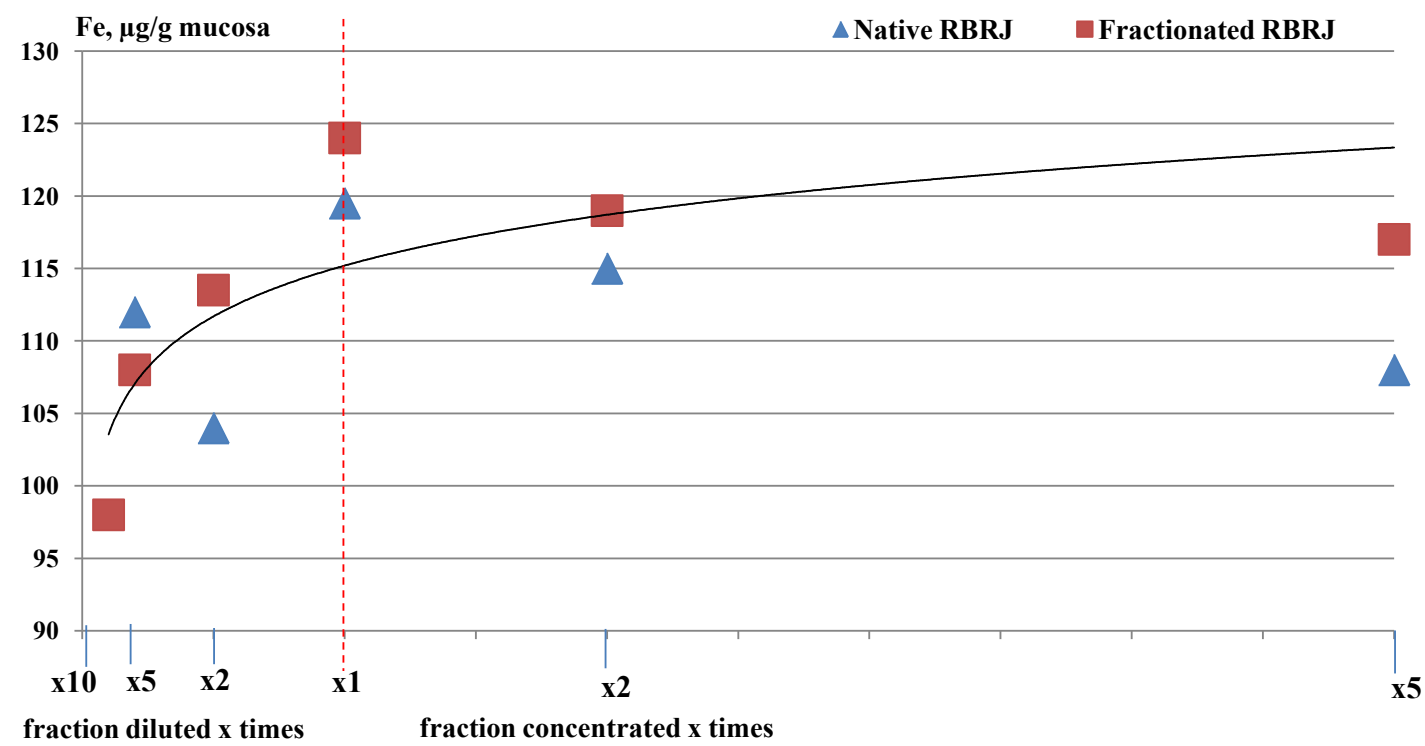

Figure 4. The effect of a single per os ingestion of native or fractionated red beetroot juice (RBRJ) on the content of iron in chicken liver in vivo.

To clarify that $B$. vulgaris pigments are responsible for the mentioned specific effect, the juice of red beet roots and colorless strains (sugar and fodder beet) was compared. Iron, red and yellow pigment concentration was higher in RBRJ than in betanin-free strains (Table 3). At the same time, sugar beetroot juice statistically significantly $(\mathrm{p}<0.03)$ enhanced iron absorption, compared with the buffer solution. It is worth noting that sugar beet fibers also can stimulate iron intestinal absorption in vivo [26].

It is known that sugars impact iron absorption in the gastrointestinal tract. Fructose v. glucose significantly lowers ferrous-iron absorption in rats [27]. In our experiment RBRJ was fermented by adding yeast. As a result, total sugar juice content decreased by 10 times, but it did not cause real change of iron ab- 
sorption in vitro (Figure 1). The explanation of such a phenomenon as well as the interaction between calcium and iron may be a lumenal event [28].

Considering the ability of RBRJ to stimulate iron intestinal absorption, and thus its potential use as an anti-anemic product, the effort to increase red beetroot specific efficacy has been made. Since it still remains unknown what $B$. vulgaris compounds are responsible for iron absorption stimulation, ultrafiltration was used to isolate such compound complexes without detailed chemical identification but taking its molecular weight as a basis. Ultrafiltration membranes with different permeability ( $1-250 \mathrm{kDa}$ ) were used (Figure 4).

The desired juice ultrafiltration fraction was identified by using two parameters: iron concentration and specific effect in vitro. RBRJ fraction III, obtained at cut-off-point $150 \mathrm{kDa}$, showed 2.5 times higher (in situ) absorption stimulating effect in comparison with native juice (Table 4).

The most unexpected fact regarding fractioned RBRJ biological effects was its dose-dependence: this pertains to iron absorption in duodenum after the product's single oral ingestion as well as to the element's accumulation in the liver. Such a phenomenon was typical for fractionated, but not for native RBRJ.

Cellular iron homeostasis is maintained by iron transport proteins that work in concert with a lot of enzymes and other cell elements. Duodenal enterocytes belong to cell types which are characterized by highly dynamic iron handling [29]. The intracellular machinery of iron absorption stimulation induced by the RBRJ compound complex is unclear. It seems ferroportin, which is an exporter of iron, as well as hepcidin are involved in this phenomenon. Hepcidin is the central player regulating the amount of iron in the body [30].

To be sure, initial steps of iron duodenal absorption (tested in vitro), as well as the subsequent events (evaluated in situ and in vivo) investigated in this study, allowed us to identify the prospective direction of clinical development of a potential product for people with iron deficiency anemia-red beetroot juice fractionated by membrane ultrafiltration.

\section{Conclusions}

The present study demonstrated that RBRJ contains a compound or a compound complex with the ability to specifically stimulate duodenal iron absorption. The mentioned red beetroot complex can be isolated by using ultrafiltration. The effect is dose dependent.

The chemical nature of $B$. vulgaris iron absorption stimulating complex is not yet known. Based on our experience, we suppose that the mentioned phenomenon may be the result of the synergic effect of some substances. The same biological effects can induce the combination of chemically different substances. The study of the chemical composition of fractionated RBRJ is now in progress.

The results of the research have prospects for clinical use. Iron deficiency anaemia is globally topical. The restoration of iron transporting machinery in the intestine in case of iron absorption disturbances by using food supplement 
or medicines, based on fractionated RBRJ improves the quality of life for millions of patients. On the other hand, iron in such "natural" formulation will have higher user's compliance and less toxicity in comparison with iron salt tablets. A similar situation is described for calcium [31].

\section{Conflicts of Interest}

The authors declare no conflicts of interest regarding the publication of this paper.

\section{References}

[1] Przybyszewska, J. and Zekanowska, E. (2014) The Role of Hepcidin, Ferroportin, HCP1, and MT1 Protein in Iron Absorption in the Human Digestive Tract. Przeglad Gastroenterologiczny, 9, 208-213. https://doi.org/10.5114/pg.2014.45102

[2] Camaschella, C. and Poggiali, E. (2011) Inherited Disorders of Iron Metabolism. Current Opinion in Pediatrics, 23, 14-20. https://doi.org/10.1097/MOP.0b013e3283425591

[3] Zimmermann, M.B. and Hurrell, R.F. (2007) Nutritional Iron Deficiency. Lancet, 370, 511-520. https://doi.org/10.1016/S0140-6736(07)61235-5

[4] Levi, M., Rosselli, M., Simonetti, M., Brignoli, O., Cancian, M., Masotti, A., Pegoraro, V., Cataldo, N., Heiman, F., Chelo, M., Cricelli, I., Cricelli, C. and Lapi, F. (2016) Epidemiology of Iron Deficiency Anaemia in Four European Countries: A Population-Based Study in Primary Care. European Journal of Haematology, 97, 583-593. https://doi.org/10.1111/ejh.12776

[5] Banjari, I., Kenjerić, D. and Mandić, M.L. (2015) What Is the Real Public Health Significance of Iron Deficiency and Iron Deficiency Anaemia in Croatia? A Population-Based Observational Study on Pregnant Women at Early Pregnancy from Eastern Croatia. Central European Journal of Public Health, 23, 122-127.

https://doi.org/10.21101/cejph

[6] Hunt, J.M. (2002) Reversing Productivity Losses from Iron Deficiency: The Economic Case. The Journal of Nutrition, 132, 794-801. https://doi.org/10.1093/jn/132.4.794S

[7] Pereira, D.I.A., Irving, S.M., Lomer, M.C.E. and Powell, J.J. (2014) A Rapid, Simple Questionnaire to Assess Gastrointestinal Symptoms after Oral Ferrous Sulphate Supplementation. BMC Gastroenterology, 14, 103.

https://doi.org/10.1186/1471-230X-14-103

http://bmcgastroenterol.biomedcentral.com/articles/10.1186/1471-230X-14-103

[8] Tiwari, A.K., Mahdi, A.A., Chandyan, S., Zahra, F., Godbole, M.M., Jaiswar, S.P., Srivastava, V.K. and Negi, M.P. (2011) Oral iron Supplementation Leads to Oxidative Imbalance in Anemic Women: A Prospective Study. Clinical Nutrition, 30, 188-193. https://doi.org/10.1016/j.clnu.2010.08.001

[9] Teucher, B., Olivares, M. and Cori, H. (2004) Enhancers of Iron Absorption: Ascorbic Acid and Other Organic Acids. International Journal for Vitamin and Nutrition Research, 74, 403-419. https://doi.org/10.1024/0300-9831.74.6.403

[10] Berzina, N., Apsite, M., Basova, N., Smirnova, G. and Isajevs, S. (2008) Influence of Different Dietary Ascorbic Levels and Storage of Iron on Oxidative Stability in Chicken Tissues. In: Tserveni-Goussi, A., et al., Eds., Advances and Challenges in Poultry Science, University Studio Press, Thessaloniki, Greece, 867-872. 
[11] Boato, F., Wortley, G.M., Liu, R.H. and Glahn, R.P. (2002) Red Grape Juice Inhibits Iron Availability: Application of an in Vitro Digestion/Caco-2 Cell Model. Journal of Agricultural and Food Chemistry, 50, 6935-6938. https://doi.org/10.1021/jf025832q

[12] Shah, M., Griffin, I.J., Lifschitz, C.H. and Abrams, S.A. (2003) Effect of Orange and Apple Juice on Iron Absorption in Children. Archives of Pediatrics and Adolescent Medicine, 157, 1232-1236. https://doi.org/10.1001/archpedi.157.12.1232

[13] Petry, N., Boy, E., Wirth, J.P. and Hurrell, R.F. (2015) Review: The Potential of the Common Bean (Phaseolus vulgaris) as a Vehicle for Iron Biofortification. Nutrients, 7, 1144-1173. https://doi.org/10.3390/nu7021144

[14] Tako, E., Beebe, S.E., Reed, S., Hart, J.J. and Glahn, R.P. (2014) Polyphenolic Compounds Appear to Limit the Nutritional Benefit of Biofortified Higher Iron Black Bean (Phaseolus vulgaris L.). Nutrition Journal, 26, 13-28.

[15] Zielińska-Dawidziak, M. (2015) Plant Ferritin-A Source of Iron to Prevent Its Deficiency. Nutrients, 7, 1184-1201. https://doi.org/10.3390/nu7021184

[16] Ninfali, P. and Angelino, D. (2013) Nutritional and Functional Potential of Beta vulgariscicla and Rubra. Fitoterapia, 89, 188-199.

https://doi.org/10.1016/j.fitote.2013.06.004

[17] Knutson, M. (2017) Iron Transport Proteins: Gateways of Cellular and Systemic Iron Homeostasis. Journal of Biological Chemistry, 292, 12735-12743. https://doi.org/10.1074/jbc.R117.786632

[18] Close, B., Banister, K., Baumans, V., Bernoth, E.M., Bromage, N., Bunyan, J., Gregory, N., Hackbarth, H., Morton, D. and Warwick, C. (1997) Recommendation for Euthanasia of Experimental Animals. Part 2. DGXT of the European Commission. Laboratory Animals, 31, 1-32. https://doi.org/10.1258/002367797780600297

[19] Ugolev, A., Zhigure, D. and Nurks, J. (1970) Accumulating Mucosal Preparation-A New Method in the Initial Stages of Substance Transport across the Intestinal Wall. Fiziologicheskiizhurnal SSSR imeni I. M. Sechenova, 56, 1638-1641.

[20] AOAC Official Method 999.11. (1999) Lead, Cadmium, Copper, Iron and Zinc in Foods Atomic Absorption Spectrophotometry after Dry Ashing.

[21] AOAC Official Method 967.21. (1967) Ascorbic Acid in Vitamin Preparations and Juices.

[22] AOAC Official Method. 974.06. (1974) Sugars (Total) in Animal Feed.

[23] Somogyi, M. (1952) Notes on Sugar Determination. Journal of Biological Chemistry, 195, 19-23.

[24] AOAC Official Method 942.06 Alcohol by Volume in Distilled Liquors Pycnometer Method.

[25] Von Elbe, J.H. (2003) Betalains. In: Wrolstad, R.E., Acree, T.E., Decker, E.A., Penner, M.H., Reid, D.S., Schwartz, S.J., Shoemaker, C.F., Smith, D. and Sporns, P., Eds., Handbook of Food Analytical Chemistry. Pigments, Colorants, Flavors, Texture, and Bioactive Food Components, John Wiley and Sons, Inc., New York, 123-131.

[26] Fairweather-Tait, S.J. and Wright, A.J.A. (1990) The Effects of Sugar-Beet Fibre and Wheat Bran on Iron and Zinc Absorption in Rats. British Journal of Nutrition, 64, 547-552. https://doi.org/10.1079/BJN19900054

[27] Brouwer, I.A., Lemmens, A.G. and Beynen, A.C. (1993) Dietary Fructose v. Glucose Lowers Ferrous-Iron Absorption in Rats. British Journal of Nutrition, 70, 171-178. https://doi.org/10.1079/BJN19930114 
[28] Lönnerdal, B. (2010) Calcium and Iron Absorption-Mechanisms and Public Health Relevance. International Journal for Vitamin and Nutrition Research, 80, 293-299. https://doi.org/10.1024/0300-9831/a000036

[29] Anantram, A., Janve, M., Degani, M., Singhal, R. and Kundaikar, H. (2018) Homology Modelling of Human Divalent Metal Transporter (DMT): Molecular Docking and Dynamic Simulations for Duodenal Iron Transport. Journal of Molecular Graphics and Modelling, 85, 145-152.

http://www.ncbi.nlm.nih.gov/pubmed/30193229

https://doi.org/10.1016/j.jmgm.2018.08.006

[30] Harigae, H. (2010) Recent Progress in Iron Metabolism and Iron-Related Anemia. The Japanese Journal of Clinical Pathology, 58, 1211-1218.

[31] Bristow, S.M., Gamble, G.D., Stewart, A., Kalluru, R., Horne, A.M. and Reid, I.R. (2015) Acute Effect of Calcium Citrate with or without a Meal, Calcium-Fortified Juice and a Dairy Product meal on Serum Calcium and Phosphate: A Randomized Cross-Over Trial. British Journal of Nutrition, 113, 1585-1594.

https://doi.org/10.1017/S000711451500080X 